\title{
Modeling power consumption by pump station control systems based on fuzzy controllers with discrete terms
}

\author{
E.A. Muravyova \\ Ufa State Petroleum Technological University, \\ Sterlitamak Branch, Russian Federation \\ e-mail: muraveva_ea@mail.ru
}

\author{
A.N. Azanov \\ Ufa State Petroleum Technological University, \\ Sterlitamak Branch, Russian Federation \\ e-mail: muraveva_ea@mail.ru
}

\author{
E.R. Enikeeva \\ Almetyevsk State Oil Institute, \\ Russian Federation \\ e-mail: elza.enikeeva@mail.ru
}

\begin{abstract}
In the article, the power consumption of pump station control systems was simulated in the iThink software package. For this purpose, simulation models of two control systems to control the oil level in the pump station were developed. In the first of these, only the frequency converter was used as a control element, and in the second one, in addition to the frequency converter, a fuzzy controller was also involved. A simulation of oil level control process, presented in a graphical form, was conducted, as well as the graphs for energy consumption of the pumps were obtained. Based on the initial and obtained data, the efficiency of the considered control systems was compared, and also dependency graphs for energy consumption of the systems using only a frequency converter and using a frequency converter and a fuzzy controller were obtained.
\end{abstract}

Analysis of simulation models showed that it is more economical and safe to use the control circuit with a frequency converter and a fuzzy controller.

Keywords-pumping station; fuzzy controller; iThink software; simulation model; power consumption.

\section{INTRODUCTION}

Research of pumping station control systems in real objects will require large investments, it will be quite long in time, may lead to undesirable consequences, and also interfere with the existing production; for these reasons a simulation modeling was used for a comparative analysis of pumping station control systems using a frequency converter only and a frequency converter and a fuzzy controller. To develop the simulation model, iThink software by High Performance Systems was used.

The authors set the goal to develop two simulation models of the oil level control system with the presentation of the control process and power consumption in a graphic form, to compare their power consumption and choose the most economical. Also in the model, it is possible to compare control systems by a sharp increase in the amount of oil supplied.

Oil-level control process data and controlled asynchronous electric drive data were used for the model development. The following input data were used: the amount of oil supplied, the initial oil level, the mainline voltage, the functional dependencies of the frequency converter and the asynchronous pump drive (AD).

In the developed model, a comparative analysis of the two control systems behavior was carried out under identical initial conditions by the sharp increase in the amount of oil supplied and in the pumps power consumption in both cases.

\section{MODELING OF PUMP STATION CONTROLLING PROCESS}

Simulation modeling allows one to apply an abstract model that possesses necessary qualities of the studied original system. Such a model does not require as much investment as a real object, can be created much faster, and also reduces the time costs $[2,3]$.

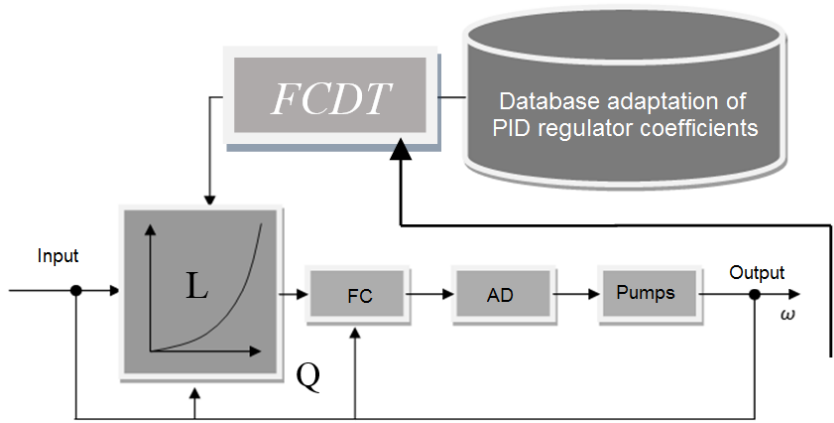

Fig. 1. Flow chart of the frequency-controlled asynchronous electric drive with the linearization unit "Input-output": FCDT - fuzzy controller with discrete terms, L - oil level, Q - oil consumption 
Figure 1 shows the flow chart of a frequency-controlled asynchronous electric drive (FCED) with a linearization block "Input-output" [5,6]. Linearization is carried out according to the system of production rules [4].

The adjustable parameters of the pump station (PS) are the level in the tank $L$ and the flow rate in the output pipelines of the pumps. The level in the PS tank should be maintained at a level of 2.5 meters (tank height $-5 \mathrm{~m}$, length $-10.2 \mathrm{~m}$ and volume $200 \mathrm{~m}^{3}$ ) that corresponds to $100 \mathrm{~m}^{3}$ [10].

The basic flow chart of the PS model is shown in figure 2.

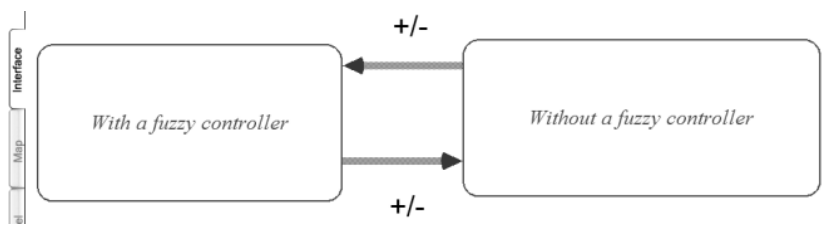

Fig. 2. Basic PS model flowchart in the "Interface" tab

The basic model flowchart contains two submodels (frames) with and without a fuzzy controller. The connector links between them reflect the impact of each submodel on the other.

In the "Model" tab, mathematical connections between the blocks are constructed. In this window there is a flow chart of the model from the built-in blocks, between which interconnections are established by arrow-connectors.

Figure 3 shows the equivalent of the functional structure of the control system of the pumping station electric drives in two ways, created in the iThink software.

The general view of the model contains the input streams «Oil supply», «Oil supply 2» and output streams «Pumps» and «Pumps 2». Flows «Oil supply» and «Oil supply 2 » show the total oil flows. «Pumps» and «Pumps 2 » are output flows, and discharge out of the tank is carried out with their help. Also in Figure 3 are shown [1]: Tanks «Tank» and «Tank 2»; functional blocks «Amount of oil supplied», «Amount of oil supplied 2», «Power grid», «Power grid $2 »,\langle\mathrm{FC} »,\langle\mathrm{FC} 2 »$, «AD», «AD 2», «Power consumption», «Power consumption $2 »$ and «Fuzzy controller». Functional blocks «Amount of oil supplied», «Amount of oil supplied 2», «Power grid», «Power grid 2» designate previously known production characteristics, «Fuzzy controller» means oil supply control using fuzzy controllers with discrete terms. The functional blocks «FC», $\langle\mathrm{FC} 2 »,\langle\mathrm{AD} »\langle\mathrm{AD} 2 »$ are a frequency converter and a pumps asynchronous electric drive.

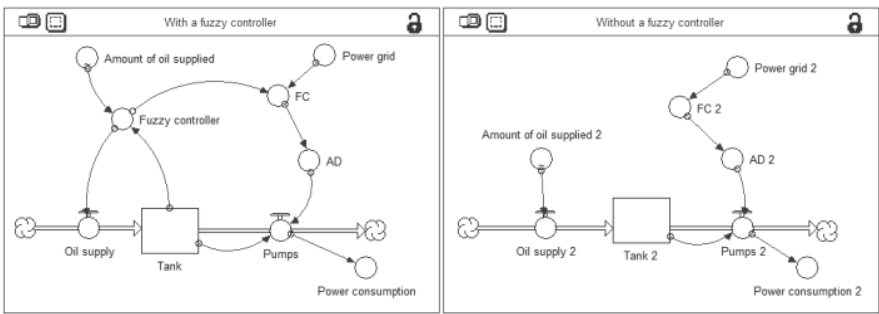

Fig. 3. A general view of the two ways model of the pump station control process in the "Model" tab
In each block, the parameter values and mathematical formulas of the functional dependence of each element in the given model are prescribed. Formulas and parameter values are set using the standard dialog boxes in the iThink software.

The amount of oil supplied is graphically set in the Graphical Function window. The amount of oil supplied plot is shown in Figure 4.

The fuzzy controller selects the degree of pump valve opening on the oil supply line, depending on the amount of oil supplied and the Tank level (figure 5). In figure 6, the oil supply is set depending on the output signal of the fuzzy controller [5].

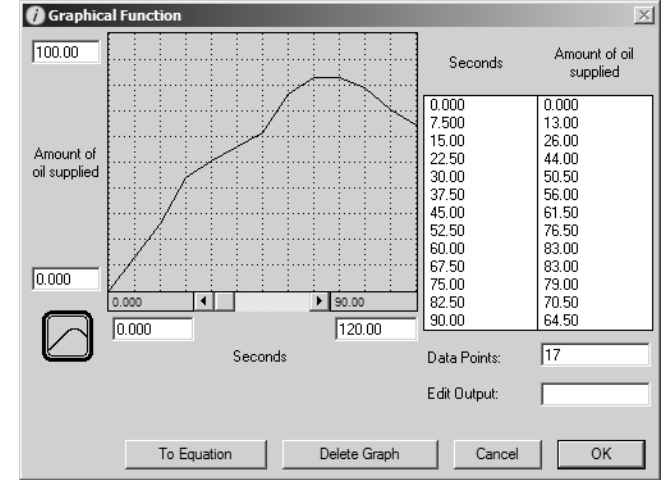

Fig. 4. Setting the amount of oil supplied in the Graphical Function window

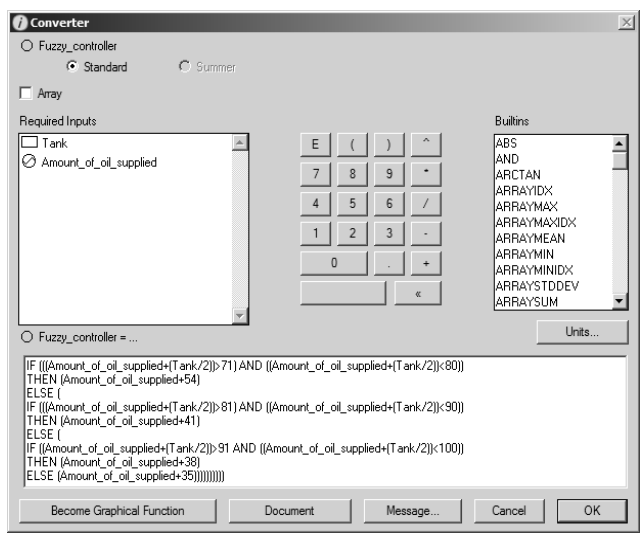

Fig. 5. Setting the fuzzy controller in the Converter window

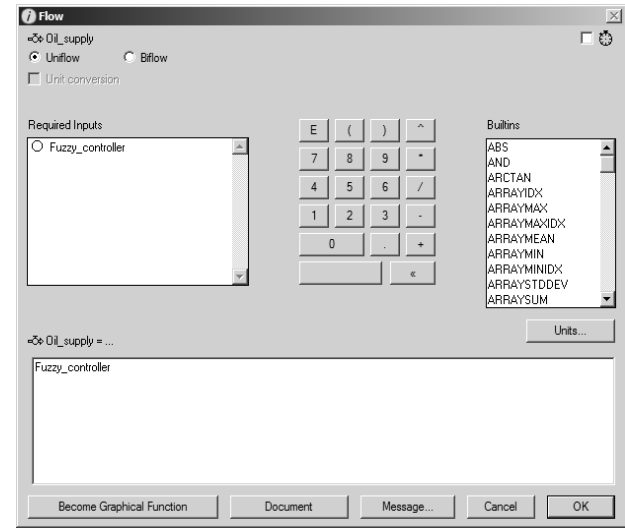

Fig. 6. Dependence of the oil supply from the output signal of the fuzzy controller, configured in the Flow window 
The main power consumer of the pumping station is the electrical drive "AD». The voltage in the power grid as a function of time is given in figure 7 [9].

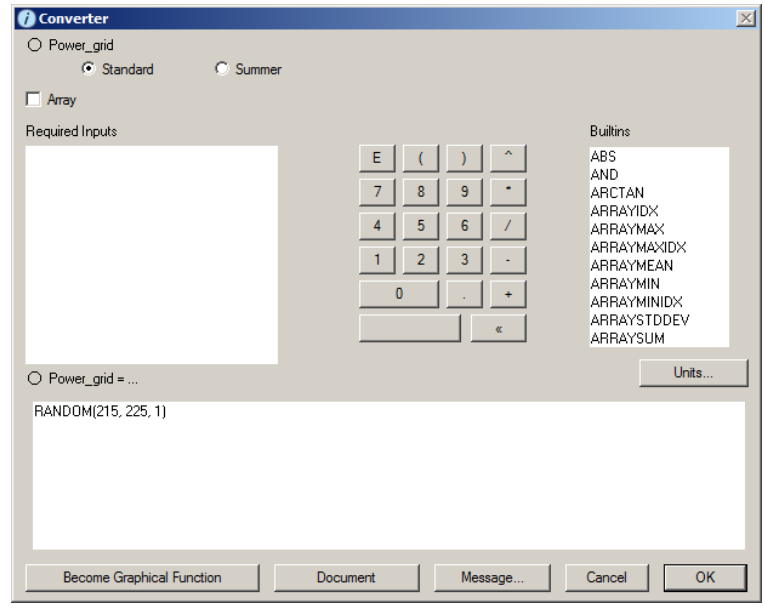

Fig. 7. Voltage in the power grid, specified in the Converter window

The electrical power that comes from the power grid must be converted before the pump's electric drive. This is done using a frequency converter ( $\langle\mathrm{FC} »)$. The transformation of the electrical power is expressed by the functional dependence shown in figure 8 [10].

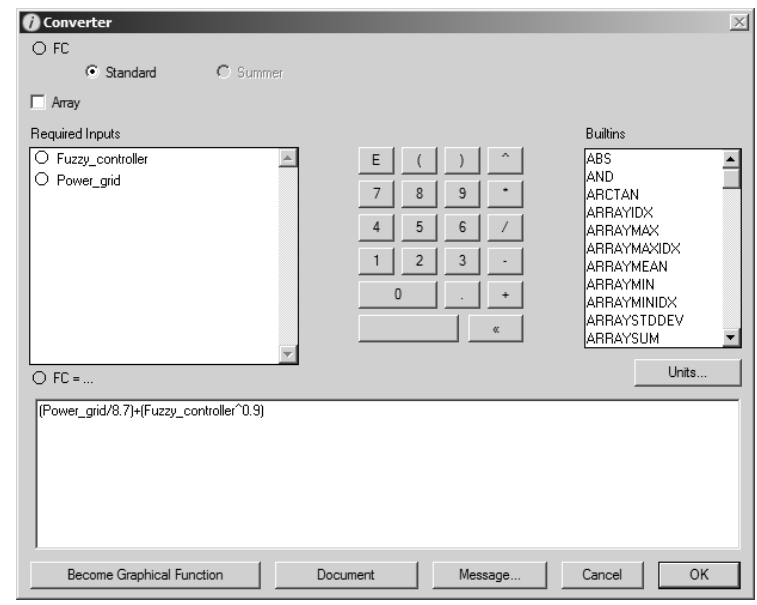

Fig. 8. Setting the function "FC" in the Converter window in the case of using a fuzzy controller

The pump operates from an asynchronous electric drive, electric power is supplied to it from the frequency converter. This dependency is specified using the Converter window [9].

The initial value of the tank level is set using the Stock window and is zero. The level is controlled and maintained by the fuzzy controller based on the equation by pumps on inlet pipelines.

The functional dependence of the model element «Pumps» is shown in figure 9 .

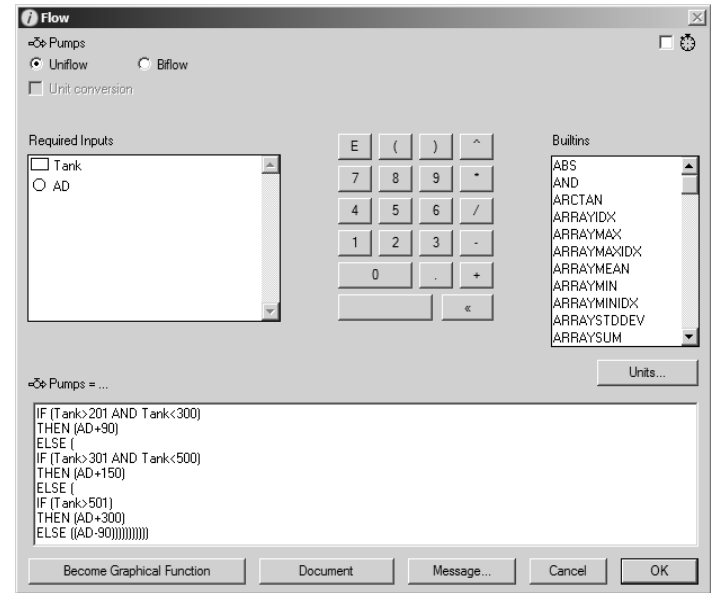

Fig. 9. Functional dependence of the model element «Pumps»

The parameters of the control system using only the frequency converter are shown in figures 10,11, and also in the description below.

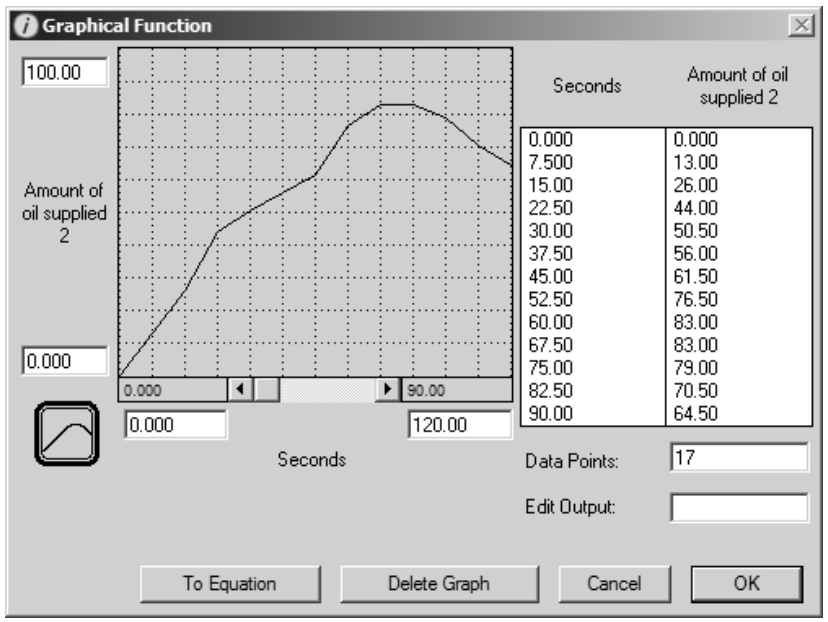

Fig. 10. - Setting the amount of oil supplied in the Graphical Function window

Data for the flow «Oil supply 2 » are taken directly from the «Amount of oil supplied 2»plot (figure 11) [6,7]

Oil_supply_2=Amount_of_oil_supplied_2.

The initial level in the tank 2 is set to zero. The level is controlled and maintained by means of flows «Oil supply 2 » and «Pumps 2» for which functional dependencies are defined.

The parameters of the block «Power grid 2» are similar to the «Power grid» (figure 7):

Power_grid_2=RANDOM $(215,225,1)$.

Electric power coming from the grid is converted using a frequency converter «FC 2» according to the following functional dependence:

FC_2 $=($ Power_grid_2/8,7). 
The mathematical dependence describing the operation of the asynchronous drive «AD 2» repeats the formula for the asynchronous drive $\langle\mathrm{AD} »$ and is equal to the $\langle\mathrm{FC}\rangle$ :

AD_2=FC_2.

The functional dependence of the model element «Pumps $2 »$ (figure 11) is as follows:

Pumps_2 = IF $($ Tank_2>0 AND Tank_2<20) THEN (AD_2-50) ELSE (

IF (Tank_2>21 AND Tank_2<40) THEN (AD_2-35) ELSE (

IF (Tank_2>41 AND Tank_2<60) THEN (AD_2-20) ELSE (

IF (Tank_2>61 AND Tank_2<80) THEN (AD_2-5) ELSE (

IF (Tank_2>81 AND Tank_2<100) THEN (AD_2+5) ELSE (

IF (Tank_2>101 AND Tank_2<120) THEN (AD_2+25) ELSE

IF (Tank_2>121 AND Tank_2<200) THEN (AD_2+45) ELSE (

IF (Tank_2>201 AND Tank_2<300) THEN (AD_2+90) ELSE (

IF (Tank_2>301 AND Tank_2<500) THEN (AD_2+150) ELSE

IF (Tank_2>501) THEN (AD_2+300) ELSE ((AD_290()))))()))))

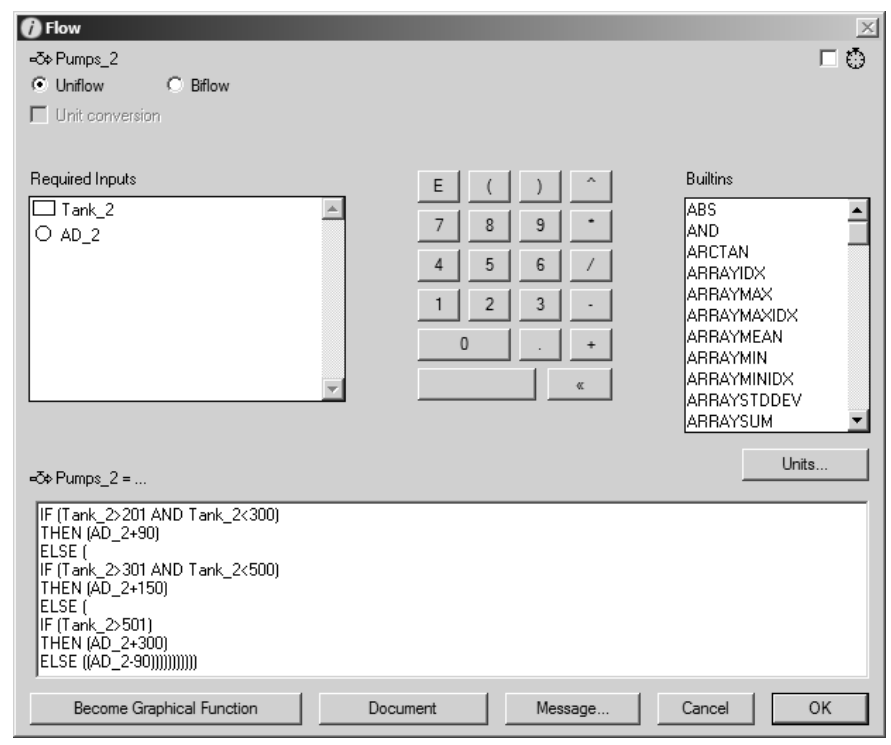

Fig. 11. Functional dependence of the model element «Pumps 2»

The Equation tab shows all the values of the specified parameters for all function blocks, functional dependencies and other customized parameters. A fragment of the Equation tab with the parameters of objects of this model is shown in figure 12 .

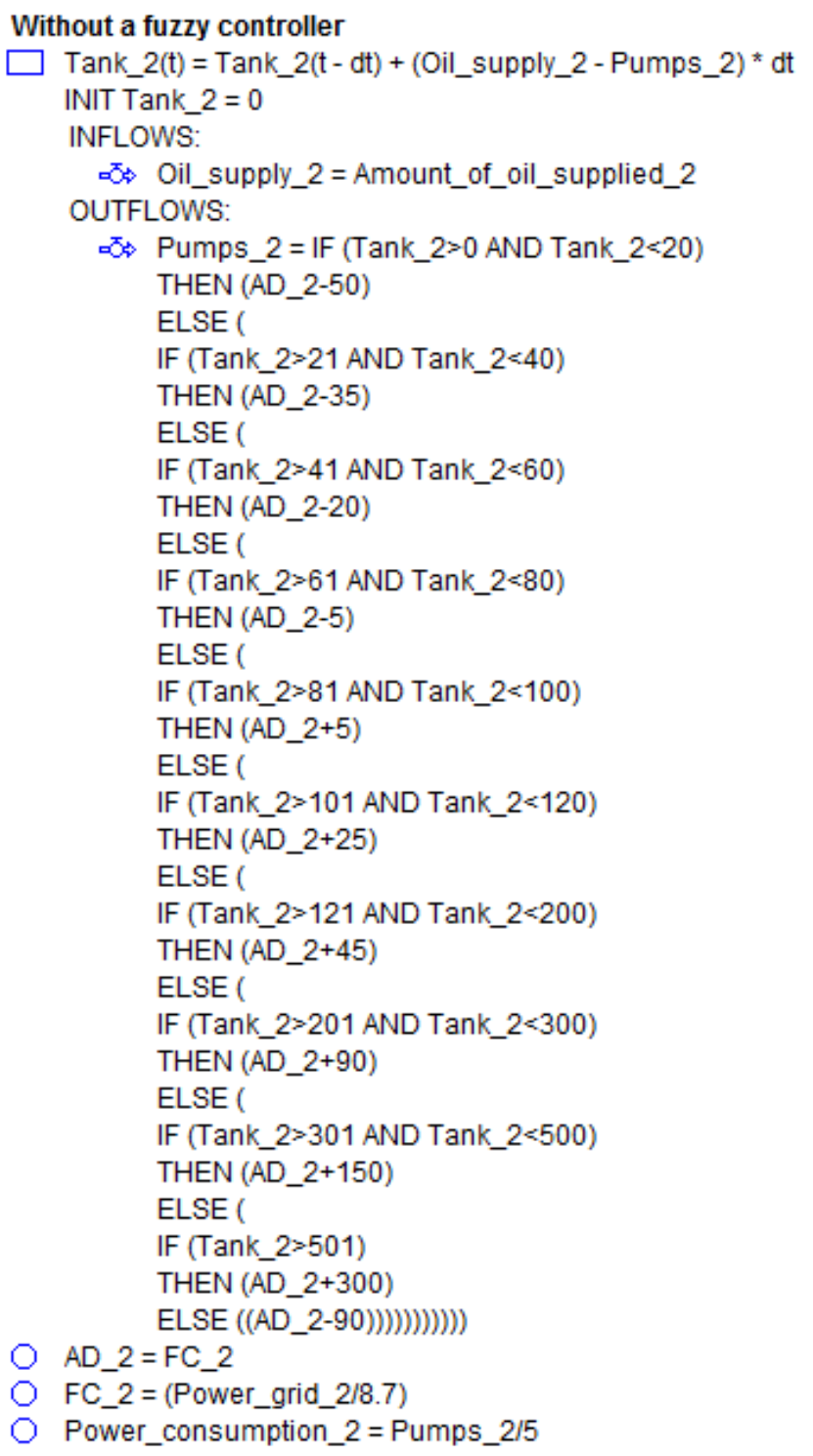

Fig. 12. Equation tab of the developed model, containing all configured parameters size.

This template has been tailored for output on the A4 paper

\section{ANALYSIS OF THE MODEL OBTAINED}

We will carry out a comparative analysis of the developed simulation models. To do this, we use 4 graphics.

The plot of the tank level versus simulation time using the fuzzy controller is shown in figure 13, the level is controlled and maintained at a value of $100 \mathrm{~m}^{3}$, which corresponds to a height of 2.5 meters of the tank (tank parameters are described above). 


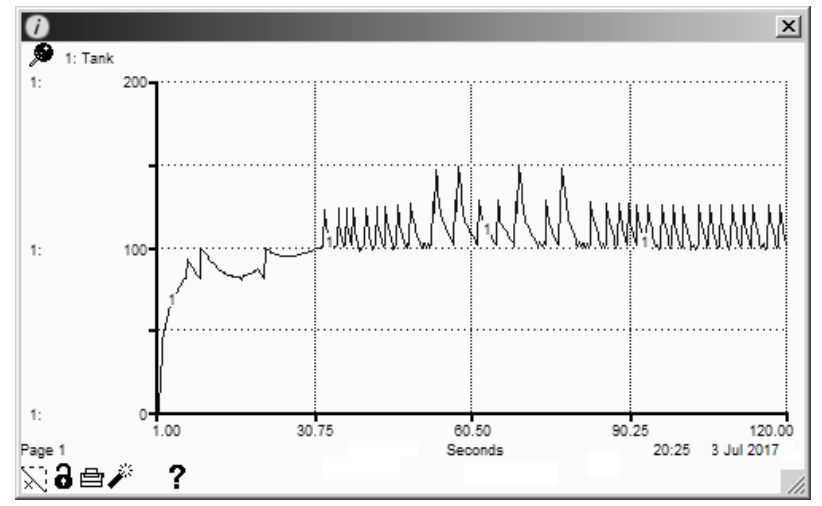

Fig. 13. The plot of the oil level versus simulation time in case of using the fuzzy controller

The plot of the oil level versus the simulation time without using the fuzzy controller is shown in figure 14. The presented plot shows that in a case of sharp increase in the oil supplied to the tank, there is a threat of overflow, as the level reaches a critical value.

If the fuzzy controller is used, leveling is carried out faster, and a sharp increase in the amount of oil supplied does not lead to a critical level values (figure 13).

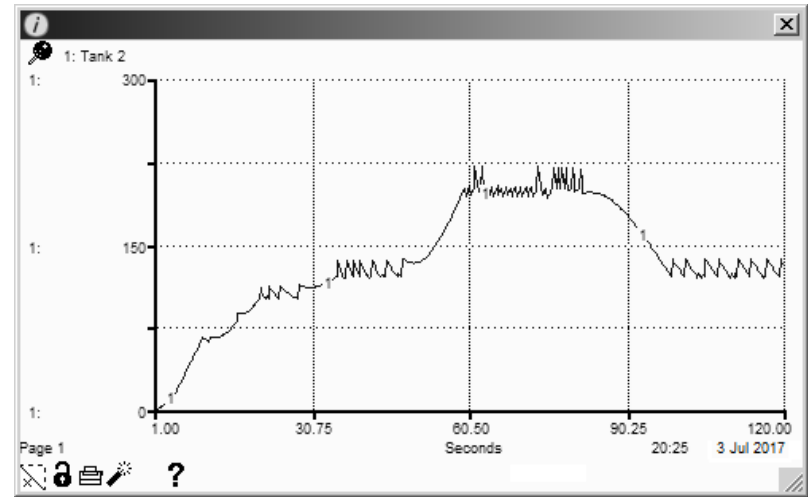

Fig. 14. The plot of the oil level versus simulation time without using the fuzzy controller

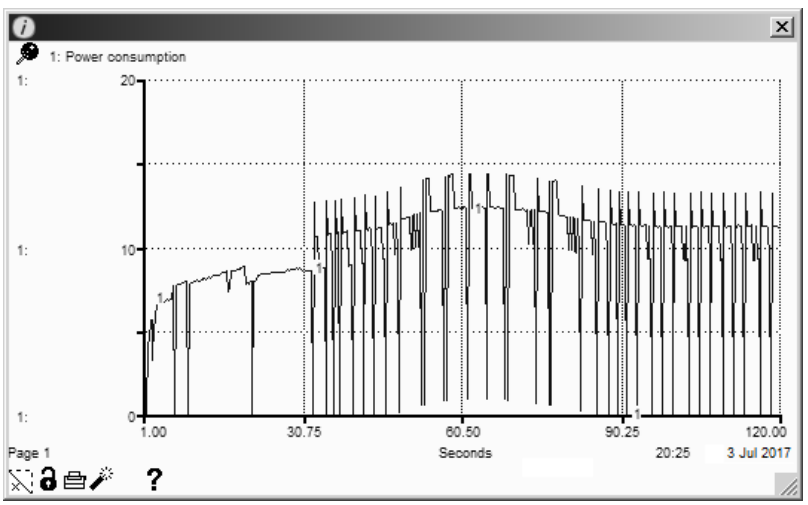

Fig. 15. Plot of Power consumption with fuzzy controller

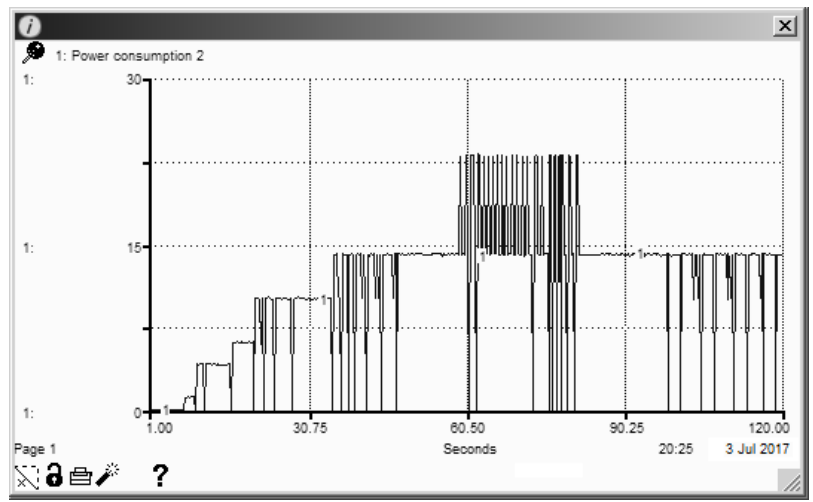

Fig. 16. Plot of power consumption without the fuzzy controller

Let us compare the power consumption in the circuit with and without the fuzzy controller, these plots are shown in figures 15 and 16.

Power consumption with the fuzzy controller is lower by an average of $20 \%$ compared to the control without the fuzzy controller. With a sharp increase in the amount of oil supplied to the tank, the power consumption in the circuit with the fuzzy controller slightly increases, and in the circuit without the fuzzy controller there is a jump in power consumption $[8,10]$.

\section{CONCLUSION}

The model of the pumping station developed in this work reflects the processes that occur when the oil level is controlled. Two circuit of oil level control and maintenance are considered - using frequency converter only and a frequency converter and a fuzzy controller.

In a system without fuzzy controller, all other things being equal, a sharp increase in the amount of oil supplied leads to a threat of liquid overflow from a tank. The energy consumption of such a system is somewhat higher, since for maintaining the level in the tank by pumps on the tank discharge more energy is expended, and a jump in energy consumption occurs.

In case of using the fuzzy controller, the leveling in the tank is much faster, a sharp increase in the amount of oil supplied does not lead to a critical level, with an average power consumption of $20 \%$ less than in a system without the fuzzy controller.

Simulation of power consumption has shown that it is more economical and safe to use a control circuit with a frequency converter and a fuzzy controller.

\section{References}

[1] Yu.A. Kuznetsov, V.I. Perova, Application of simulation modeling for the analysis of mathematical models in economic systems: educational and methodical manual, Nizhny Novgorod, 2007, pp. 98

[2] Yu.A. Shebeko, A guide to the analytical package iThink. URL: http://www.tora-centre.ru/library/reing/ta.htm (reference date: 23.05.2017).

[3] A.M. Sagdatullin, "Improving the efficiency of the control of the booster pump station on the basis of a multidimensional fuzzy controller", The gas industry, vol. 12 (731), pp. 92-96, 2015. 
[4] E.A. Muravyova, A.A. Emekeev, M.I. Sharipov, A.M. Sagdatullin, "The conceptual model of an automated booster pump station for oil and gas transportation", Intelligent Technologies for Information Processing and Management (ITIPM'2014) Proceedings of the 2nd International Conference, pp. 10-13, 2014.

[5] A.M. Sagdatullin, "Development of a control system model for a pumping station based on a multidimensional fuzzy controller with discrete terms", Automation, telemechanization and communication in the oil industry, vol. 8, pp. 46-50, 2015.

[6] A.M. Sagdatullin, "Improving the control of a booster pump station based on multidimensional fuzzy controllers with discrete terms", Synopsis of a Thesis, 2016, pp. 17.

[7] A.M. Sagdatullin, "Development of a control system model for a pumping station based on a multidimensional fuzzy controller with discrete terms", Automation, telemechanization and communication in the oil industry, vol. 8, pp. 46-50, 2015.
[8] A.M. Sagdatullin, "Intellectual control of the operating modes of oil pumping stations", The Energy Institute of Tomsk Polytechnic University, vol. 2 pp. 128-131, September - October 2015 [Intelligent power systems: Writings of the III International Youth Forum, pp. 256, 2015]

[9] E.A. Muravyova, E.A. Shulaeva, P.N. Charikov, R.R. Kadyrov, M.I. Sharipov, A.V. Bondarev, A.F. Shishkina, "Optimization of the structure of the control system using the fuzzy controller", Procedia Computer Science, vol. 120, pp. 487-494, August 2017 [9th International Conference on Theory and Application of Soft Computing, Computing with Words and Perception, (ICSCCW 2017), pp. 726, 2017]

[10] E.A. Muravyova, A.M. Sagdatullin, A.A. Emekeev, "Intellectual control of oil and gas transportation system by multidimensional fuzzy controllers with precise terms", Applied Mechanics and Materials, vol. 756, pp. 633, 2015. 